\title{
Perbandingan Fasilitas Penunjang Kesiapsiagaan SD, SMP, dan SMA Terhadap Bencana Gempa Di Kota Yogyakarta
}

\author{
(Comparison of Support Facilities for Elementary, Middle, and High School Preparedness for Earthquake \\ Disaster in Yogyakarta City)
}

FAJAR KABISATYO TRI NUGROHO

\begin{abstract}
ABSTRAK
Gempa bumi merupakan salah satu bencana yang paling dahsyat dan datang dengan tiba-tiba, yang dapat menghancurkan bangunan dalam waktu singkat. Catatan sejarah menunjukkan bahwa Jawa Tengah dan Daerah Istimewa Yogyakarta sering mengalami gempa bumi. Gempa tektonik berkekuatan di atas 6 Richter Scale (RS) dan bahkan di atas 7 RS terjadi pada 1867, 1943, 1981, 2001 dan terakhir terjadi pada Sabtu, 27 Mei 2006. Di Kota Yogyakarta, terdapat 27 bangunan sekolah yang rusak akibat gempa 27 Mei. Penelitian ini bertujuan untuk mengevaluasi sarana dan prasarana sekolah untuk mendukung kesiapsiagaan bencana serta untuk mengetahui tingkat kesiapan sekolah terhadap bencana gempa 2006. Metode penelitian menggunakan likert scale dan diproses menggunakan Ms. Excel dan SPSS sedangkan pengumpulan data dilakukan dengan penilaian langsung di sekolah. Hasil penelitian menunjukkan bahwa 50,63\% dari 90 sekolah di Kota Yogyakarta tidAK memiliki fasilitas penunjang kesiapsiagaan bencana, 15,45\% memiliki fasilitas penunjang namun tidak sesuai standar atau tidak layak, sisanya sebesar 33,9\% memiliki fasilitas penunjang dan sesuai standar.
\end{abstract}

Kata kunci: gempa bumi, kesiapsiagaan bencana, sekolah

\section{ABSTRACT}

Earthquakes are one of the most devastating natural disasters and come suddenly, this disaster can destroy buildings in a short time. Central Java and the Special Region of Yogyakarta in historical records have often experienced earthquakes, recently tectonic earthquakes of magnitude above 6 Richter Scale (RS), and some even reach more than 7 RS, which occurred in 1867, 1943, 1981, 2001 and the last occurred on Saturday, May 27, 2006. In Yogyakarta city itself, there are 27 school buildings damaged by the 27 May earthquake. This study aimed to evaluate school facilities and infrastructure to support earthquake disaster preparedness and find out the level of school readiness 2006 earthquake disaster. The research method used likert scale and processed using Ms.Excel and SPSS, data colleting use direct assessment at school. The results show form 90 schools in the city of Yogyakarta showed $50.63 \%$ of the schools did not have disaster preparedness support facilities, $15.45 \%$ had facilities but were not standard or not feasible, the remaining $33.9 \%$ owned facilities and according to standards.

Keywords: Earthquake, Disaster Preparedness, school

\section{PENDAHULUAN}

Indonesia yang terdiri dari gugusan kepulauan mempunyai potensi bencana yang sangat tinggi dan juga sangat bervariasi dari aspek jenis bencana. Kondisi alam tersebut serta adanya keanekaragaman penduduk dan budaya di Indonesia menyebabkan timbulnya risiko terjadinya bencana alam, bencana ulah manusia, 
dan kedaruratan kompleks. Yogyakata termasuk wilayah yang mempunyai risiko bencana yang sangat beragam, di sisi lain Yogyakarta menjadi daerah yang memiliki perkembangan sangat pesat dalam hal ekonomi, pendidikan, dan pembangunan gedung maupun infrastrukur lain.

Gempa bumi merupakan salah satu bencana alam yang sangat dahsyat dan datang secara tiba-tiba. Bencana ini dapat merusak dan menghancurkan bangunan dalam waktu yang sangat cepat serta dapat melukai bahkan menewaskan orang-orang yang berada di lokasi saat gempa itu terjadi. Menurut Howell (1990), gempa bumi adalah getaran yang terjadi pada permukaan bumi yang bersifat sementara dan kemudian menyebar ke segala arah yang diakibatkan oleh pelepasan energi dari dalam secara tiba-tiba, hal senada dituliskan dalam FEMA (2015) yang mengatakan bahwa gempa adalah terjadinya gerakan di sepanjang patahan (fault), merupakan zona tipis batuan yang memisahkan kerak. Ketika satu blok tiba-tiba tergeser dan bergerak relatif terhadap yang lain sepanjang patahan, energi yang dilepaskan menimbulkan getaran yang disebut gelombang seismik yang memancar melalui kerak ke permukaan bumi yang menyebabkan tanah bergetar.

Gempa yang terjadi pada permukaan bumi tidak membahayakan secara langsung bagi manusia, namun dampak untuk lingkungan alami dan buatan yang terkena akan menimbulkan potensi bahaya dan kerugian untuk manusia. FEMA (2015) berisi tentang penjelasan dampak gempa yang dapat membahayakan lingkungan alami, antara lain:

a. Tanah longsor (landslides) atau longsoran salju (avalanches).

b. Patahan permukaan (surface faulting), di mana tanah sepanjang satu sisi patahan mengalami dislokasi horizontal atau vertikal terhadap tanah di sisi lain.

c. Tsunami dapat dipicu oleh longsor bawah laut yang disebabkan gempa atau karena patahan permukaan yang terjadi di dasar laut.

d. Liquifaksi (liquefaction), hal ini merupakan suatu proses atau kejadian berubahnya sifat tanah dari keadaan padat menjadi keadaan cair yang menyebabkan kekuatan tanah berkurang.

Daerah Jawa Tengah dan Daerah Istimewa Yogyakarta berdasarkan catatan sejarah sudah sering mengalami gempa, yakni gempa tektonik yang berkekuatan di atas 6 Skala Richter (SR), bahkan ada yang mencapai lebih dari 7 SR yang terjadi pada tahun 1867, 1943, 1981, 2001, dan yang terakhir terjadi pada hari Sabtu tanggal 27 Mei 2006 pagi, pukul 05.59, dengan durasi 59 detik (Winardi, 2006). Di Kota Yogyakarta sendiri terdapat 27 gedung sekolah yang rusak akibat gempa 27 Mei 2006 (tempo.co, $31 \mathrm{Mei}$ 2006), pada saat gempa terjadi kebanyakan sekolah tersebut belum mempunyai sarana prasarana yang menunjang penanggulangan terhadap bencana.

Alhamda (2012) dalam penelitiannya menyebutkan sekolah yang sudah menjadi Sekolah Siaga Bencana (SSB) lebih siap dalam menghadapi bencana dibandingkan sekolah yang belum siap secara kebijakan maupun sarana prasarana lainnya. Di samping itu Dhiroh (2013) mendapat hasil yang berbeda dalam penelitian terhadap sekolah SSB dan non SSB di Kecamatan Kretek, sekolah SSB maupun non SSB tidak mempunyai perbedaan signifikan dalam kesiapsiagaan bencana.

Permasalahan yang terjadi pada sarana prasana kesiapsiagaan bencana gempa bumi adalah belum adanya data tentang ketersediaan sarana prasana secara terukur untuk menanggulangi bencana, sarana seperti fasilitias sekolah pasca bencana gempa bumi Yogyakarta tahun 2006.

\section{Metode Penelitian}

Lokasi penelitian berada di Kotamadya Yogyakarta, dengan obyek penelitian adalah 90 sekolah yang terdiri dari 30 SD, 30 SMP, dan 30 SMA. Metode pengambilan sampel terhadap suatu populasi untuk setiap penelitian berbedabeda tergantung sampel seperti apa yang dibutuhkan oleh peneliti. Dalam penelitian ini sampel diambil dengan teknik simple random sampling yaitu teknik pengambilan anggota sampel dari populasi dilakukan secara acak (Sugiyono, 2007).

Analitik Deskriptif menurut Sugiyono (2007) adalah analisis statistik yang berfungsi untuk mendiskripsikan atau memberi gambaran terhadap obyek yang diteliti melalui data sampel atau populasi, tanpa melakukan analisis dan membuat kesimpulan yang berlaku untuk umum. Hasil dari statistik ini hanya berupa gambaran umum hasil penelitian seperti nilai maksimum, nilai minimum, mean, median, modus, dan standar deviasi. 
Analisa rata-rata dapat dilakukan dengan menggunakan persamaan berikut:

$$
\bar{x}=\frac{\sum_{i=1}^{n} x_{i}}{n}
$$

Keterangan:

$\bar{x}=$ rata-rata hitung

$x_{i}=$ nilai sampel ke-i

$n=$ jumlah sampel

Data yang sudah terkumpul kemudian dikelompokan dan dianalisis menggunakan Ms.Excel ditunjukan pada Tabel 1 dan diolah dengan menggunakan metode statistik deskriptif. Berdasarkan kajian dan evaluasi ditarik suatu kesimpulan dan perbandingan menyeluruh terhadap kondisi fasilitas sekolah SD, SMP, SMA di Kota Yogyakarta.

\section{HASIL DAN PEMBAHASAN}

Dalam penelitian ini ditentukan sampel pada setiap tingkatan sekolah diambil 30 sampel. Evaluasi fasilitas penunjang yang dilakukan dalam penelitian ini menggunakan metode survei langsung ke lapangan, dengan spesifikasi yang sesuai pada PERMEN PU NO: 45/PRT/M/2007. Sebagai contoh dokumentasi salah satu sekolah yang mempunyai tanda jalur evakuasi dan titik kumpul sesuai dengan peraturan. Sekolah tersebut adalah SMPN 4 Yogyakarta, dokumentasi ditunjukan pada Gambar 1 hingga Gambar 4.

TABEL 1. Daftar nama sekolah

\begin{tabular}{|c|c|c|c|}
\hline No & SMA & SMP & SD \\
\hline 1 & SMA N 2 Yogyakarta & SMPN 1 Yogyakarta & SDN Tahunan \\
\hline 2 & SMA N 4 Yogyakarta & SMPN 2 Yogyakarta & SDN Prawirotaman \\
\hline 3 & SMA N 5 Yogyakarta & SMPN 3 Yogyakarta & SDN Golo \\
\hline 4 & SMA N 8 Yogyakarta & SMPN 4 Yogyakarta & SDN Inti Glagah \\
\hline 5 & SMA N 9 Yogyakarta & SMPN 5 Yogyakarta & SDN 1 Kintelan \\
\hline 6 & SMA N 10 Yogyakarta & SMPN 6 Yogyakarta & SDN 2 Kintelan \\
\hline 7 & SMA N 11 Yogyakarta & SMPN 8 Yogyakarta & SDN 2 Sukorasan \\
\hline 8 & SMA BOPKRI 1 & SMPN 9 Yogyakarta & SDN Karanganyar \\
\hline 9 & SMA BOPKRI 2 & SMPN 10 Yogyakarta & SDN Timuran \\
\hline 10 & SMA Muhammadiyah 2 & SMPN 11 Yogyakarta & SD Kanisius 1 Wirobrajan \\
\hline 11 & SMA Muhammadiyah 7 & SMPN 12 Yogyakarta & SDN 1 Tamansari \\
\hline 12 & MAN 1 Yogyakarta & SMPN 13 Yogyakarta & SDN Tegalmulyo Pakuncen \\
\hline 13 & MAN 2 Yogyakarta & SMPN 15 Yogyakarta & SDN Sindurejan \\
\hline 14 & SMA STECE 1 & SMPN 16 Yogyakarta & SD Muhammadiyah 3 Wirobrajan \\
\hline 15 & SMA STECE 2 & SMP Muhammadiyah 1 & SDN 1 Terbansari \\
\hline 16 & SMA PIRI 1 & SMP Muhammadiyah 2 & SD Muhammadiyah 2 Purwodiniingratan \\
\hline 17 & SMK 3 PIRI & SMP Muhammadiyah 3 & SD Tarakanita \\
\hline 18 & SMK N 7 & SMP Muhammadiyah 5 & SDN 1 Bangirejo \\
\hline 19 & SMA Bhingka & SMP Muhammadiyah 6 & SDN Bumijo \\
\hline 20 & SMA IT ABU BAKAR & SMP Muhammadiyah 7 & SDN 1 Tumbuh \\
\hline 21 & SMA SANTA MARIA & SMP Muhammadiyah 10 & SDN Gondolayu \\
\hline 22 & SMK Koperasi Yogyakarta & SMP Bopkri 1 & SDN Gedongkuning \\
\hline 23 & SMA Budaya Wacana & SMP Bopkri 2 & SDN Tukangan \\
\hline 24 & SMA Budi Luhur & SMP Bopkri 3 & SDN 1 Lempuyangan \\
\hline 25 & SMA Santu Thomas & SMP Stela Duce 1 & SDN Tegalpanggung \\
\hline 26 & SMA BIAS & SMP 1 Piri & SDN Widoro \\
\hline 27 & SMA Gajah Mada & SMP Taman Dewasa Jetis & SDN Lempuyangwangi \\
\hline 28 & SMA Gotong Royong & SMP Budaya Wacana Gayam & SDN Warungboto \\
\hline 29 & SMK SMTI & SMP IT Masjid Syuhada & SDN Jetisharjo \\
\hline 30 & SMA Taman Madya Tamsis & SMP Kanisius Gayam & SDN 1 Jetis \\
\hline
\end{tabular}




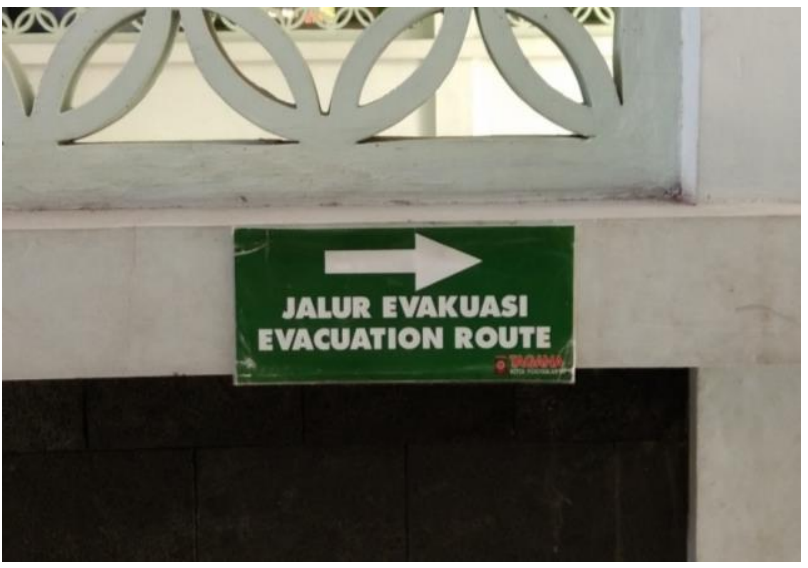

GAMBAR 1. Rambu jalur evakuasi

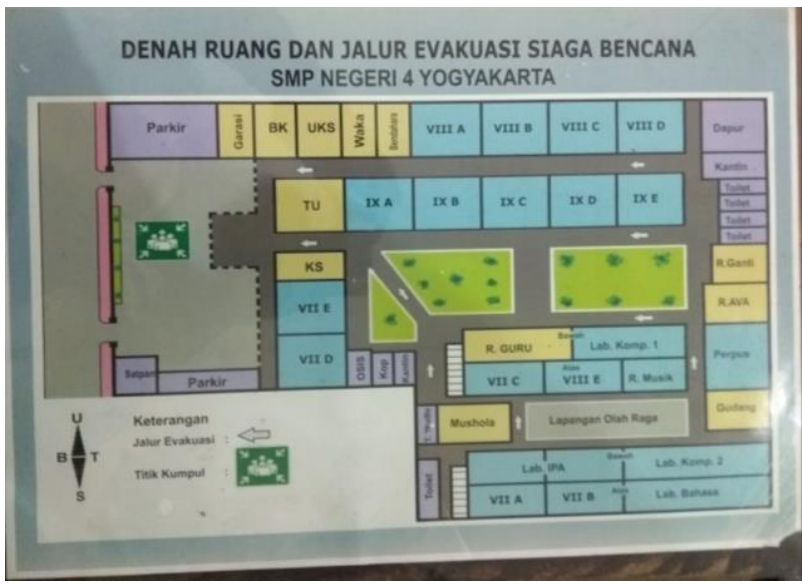

GAMBAR 3. Peta jalur evakuasi

Gambar 1 menunjukkan adanya rambu jalur evakuasi yang sesuai dengan peraturan yang berbunyi: Sarana jalur evakuasi harus dilengkapi dengan tanda arah yang mudah dibaca dan jelas (PP No. 36 2005).

Gambar 2 menunjukkan adanya titik kumpul evakuasi yang sesuai dengan peraturan yang berbunyi: Titik kumpul/assembly point adalah suatu tempat yang aman di dalam bangunan gedung, seperti:

a) yang tidak ada ancaman api.

b) dari sana penghuni bisa secara aman berhambur setelah menyelamatkan diri dari keadaan darurat menuju jalan atau ruang terbuka, (PERMEN PU NO. 26 2008)

Gambar 3 menunjukkan adanya jalur peta evakuasi yang sesuai peraturan yang berbunyi: Sarana jalur evakuasi harus dilengkapi dengan

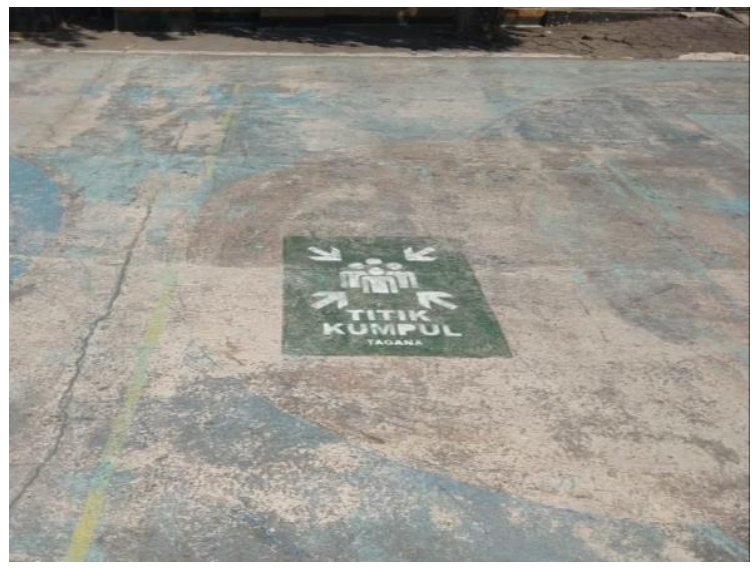

GAMBAR 2. Tanda tempat titik kumpul jalur evakuasi

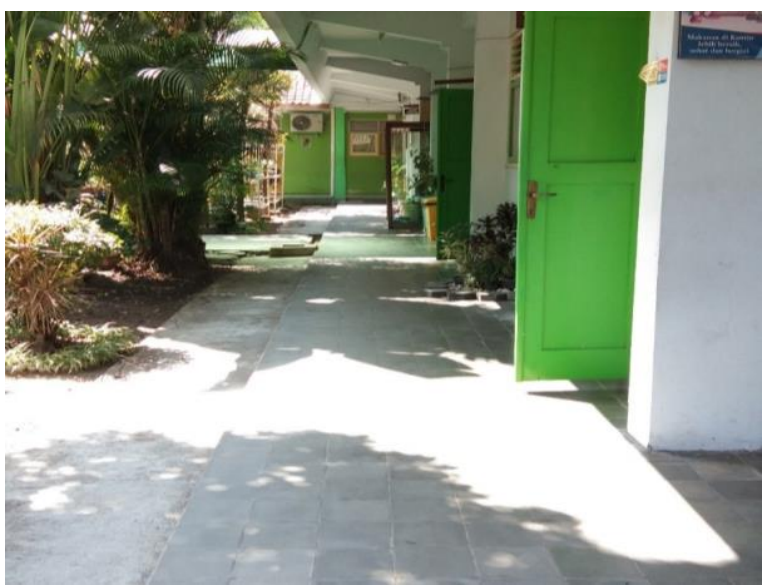

GAMBAR 4. Lorong sekolah untuk jalur evakuasi

tanda arah yang mudah dibaca dan jelas (PP No. 36 2005)

Gambar 4 menunjukkan adanya lorong sekolah yang bisa berfungsi sebagai jalur evakuasi pada saat terjadi bencana. Sesuai dengan peraturan yang berbunyi:

a) Lebar koridor bersih minimum 1,80 m;

b) Jarak setiap titik dalam koridor ke pintu darurat atau arah keluar yang terdekat tidak boleh lebih dari $25 \mathrm{~m}$;

c) Koridor harus dilengkapi dengan tandatanda penunjuk yang menunjukkan arah ke pintu darurat atau arah keluar;

d) Panjang gang buntu maksimum $15 \mathrm{~m}$ apabila dilengkapi dengan sprinkler dan $9 \mathrm{~m}$ tanpa sprinkler. (PERMEN PU NO. 45/PRT/M/2007)

Daftar lengkap fasilitas pendukung yang diteliti disajikan dalam Tabel 2. 
TABEL 2. Daftar fasilitas yang diteliti

\begin{tabular}{cl}
\hline No. & \multicolumn{1}{c}{ Fasilitas } \\
\hline 1 & Tanda Exit Darurat \\
2 & Tangga Penyelamat \\
3 & Pintu Darurat \\
4 & Koridor \\
5 & Peta Jalur Evakuasi \\
6 & Rute Evakuasi Primer \\
7 & Rute Evakuasi Alternatif \\
8 & Simbol Menuju Rute Evakuasi \\
9 & Simbol Sepanjang Rute \\
10 & Jalan Keluar Darurat \\
11 & Titik Lokasi Berkumpul \\
\hline
\end{tabular}

Hasil dari penilaian langsung pada 90 sekolah ditunjukkan pada Gambar 5 hingga Gambar 7. Kondisi fasilitas penunjang untuk tingkat SMA disajikan pada Gambar 5 yang menunjukkan kondisi fasilitas tingkat SMA di Kota Yogyakarta dengan presentase $48 \%$ fasilitas tidak tersedia, $36 \%$ fasilitas tersedia, dan $16 \%$ fasilitas tersedia tetapi tidak sesuai dengan standar.
Gambar 6 menunjukkan kondisi fasilitas tingkat SMP di Kota Yogyakarta dengan presentase $55 \%$ fasilitas tidak tersedia, $28 \%$ fasilitas tersedia, dan $17 \%$ fasilitas tersedia tetapi tidak sesuai dengan standar. Gambar 7 menunjukkan kondisi fasilitas tingkat smp di Kota Yogyakarta dengan presentase 54\% fasilitas tidak tersedia, 29\% fasilitas tersedia, dan $17 \%$ fasilitas tersedia tetapi tidak sesuai dengan standar.

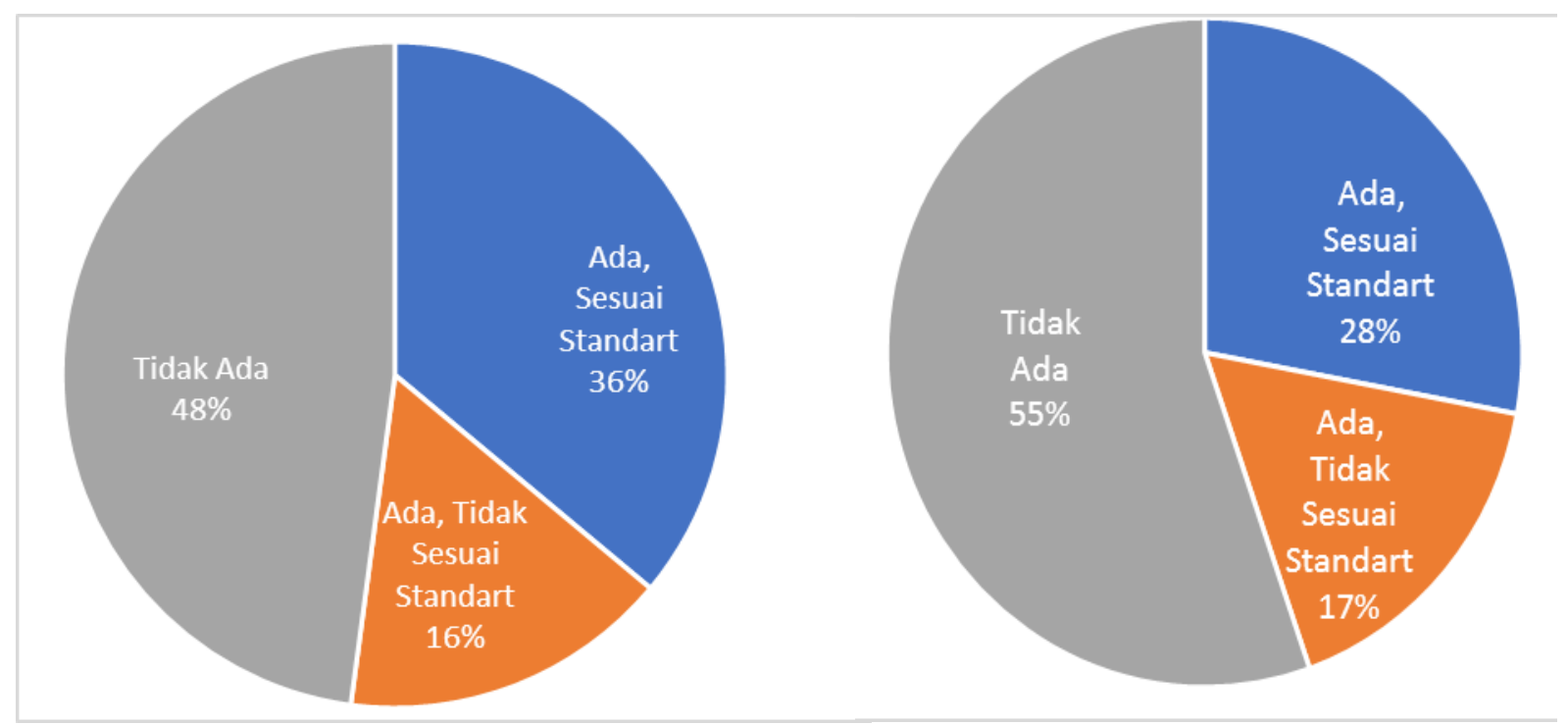

GAMBAR 5. Diagram lingkaran kondisi fasilitas

GAMBAR 6. Diagram lingkaran kondisi fasilitas SMP SMA 


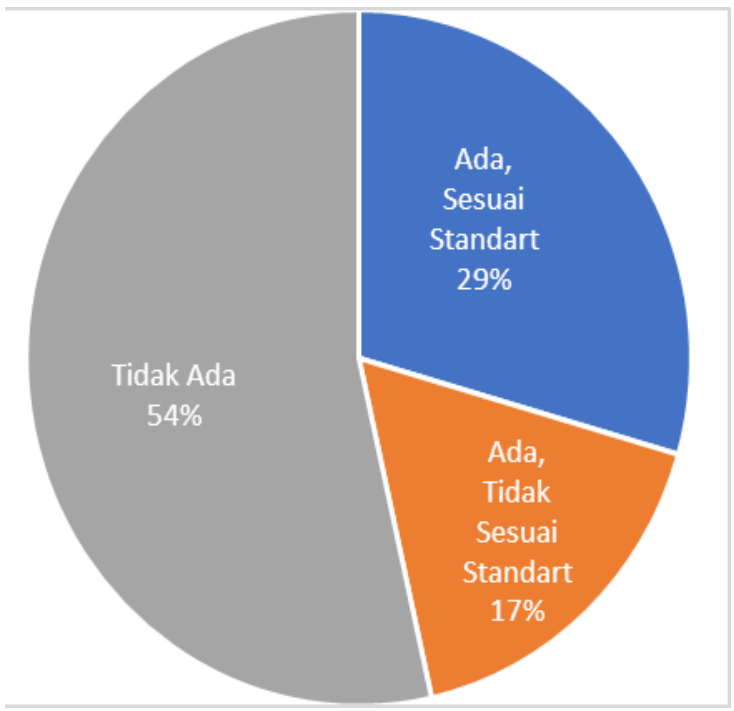

GAMBAR 7. Diagram lingkaran kondisi fasilitas SD

Secara menyeluruh kondisi fasilitas penunjang kesiapsiagaan bencana dipaparkan dalam Gambar 8 yang menunjukkan sebagian besar dari 90 sekolah di Kota Yogyakarta menunjukkan hasil 50,63\% sekolah sama sekali tidak memiliki fasilitas penunjang kesiapsiagaan bencana, $15,45 \%$ memiliki fasilitas namun tidak sesuai standar ataupun tidak layak, sisanya sebesar 33,9\% mempuyai fasilitas dan sesuai dengan standar.

Kondisi fasilitas penunjang kesiapsiagaan bencana tersebut menggambarkan bahwa sebagian besar sekolah dalam berbagai tingkat pendidikan tidak siap dalam menghadapi bencana gempa bumi. Hal tersebut mengakibatkan resiko adanya korban apabila terjadi bencana. Di samping itu perhatian sekolah terhadap fasilitas tersebut harus ditingkatkan, mengingat Kota Yogyakarta merupakan kawasan rawan bencana gempa bumi.

\section{KESIMPULAN}

Dari hasil evaluasi didapatkan fakta bahwa fasilitas penunjang yang tersedia di sekolah tidak dalam kondisi ideal, pada tingkat SD dan SMP seharusnya fasilitas harus lebih memadai dibandingkan dengan tingkat SMA, dikarenakan tingkat kemampuan untuk bertindak dari segi fisik dan pola pikir dalam menghadapi bencana murid sekolah SD dan SMP lebih rendah dibandingkan murid tingkat SMA. Secara umum kondisi fasilitas penunjang kesiapsiagaan bencana kurang

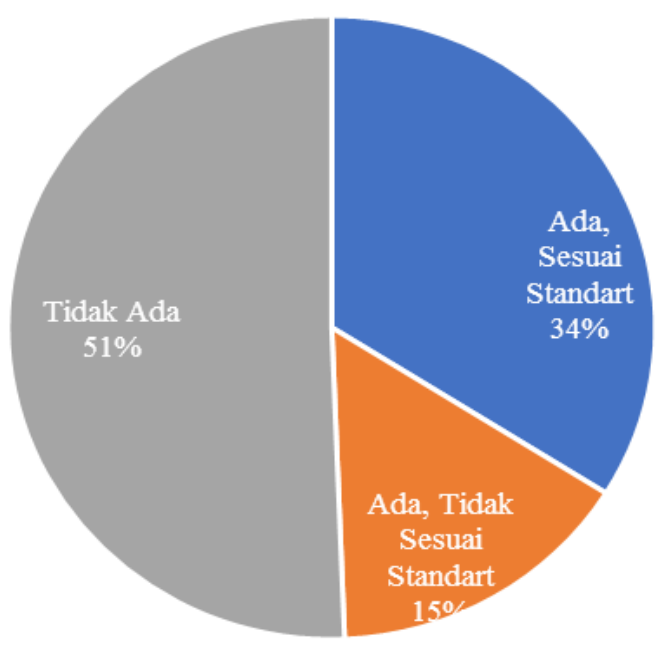

GAMBAR 8. Diagram fasilitas 90 sekolah

memadai dikarenakan lebih dari $54 \%$ fasilitas tidak tersedia, dan $17 \%$ fasilitas tersedia namun tidak sesuai standar.

\section{DAFTAR PUSTAKA}

Alhamda, S. (2011). Gambaran Kesiapan Sekolah Dasar di Zona Merah Menghadapi Benca Gempa dan Tsunami Kota Padang. Skripsi. Depok: Fakultas Kesahatan Masyarakat Universitas Indonesia

BNPB (2012). Peraturan Kepala BNPB No.2 Tahun 2012. Pedoman Umum Kajian Resiko Bencana . Jakarta

Dhiroh, A.S. (2013). Studi Komparasi Tingkat Kesiapsiagaan Komunias Sekolah Siaga Bencana Dengan Sekolah Non Siaga Bencana Dalam Mengantisipasi Ancaman Gempa Bumi Dan Tsunami Di Kecamatam Kretek Kabupaten Bantul, Tesis. Yogyakarta: Universitas Gadjah Mada.

FEMA P-154 (2015). Rapid Visual Screening of Buildings for Potential Seismic Hazards: A Handbook Third Edition. Washington, DC: FEMA.

Howell,Jr B. F. (1990). Introduction to Seismological Research: History and Development. Cambridge, UK: Cambridge University Press.

Https://Nasional.Tempo.co/read/78216/ratusan -gedung-sekolah-rusak-akibat-gempa 
Peraturan Menteri Pekerjaan Umum Nomor: 45/PRT/M/2007 Tentang Pedoman Teknis Pembangunan Bangunan Gedung Negara, Menteri Pekerjaan Umum Republik Indonesia

Peraturan Menteri Pekerjaan Umum Nomor : 26/prt/m/2008 Tentang Persyaratan Teknis Sistem Proteksi Kebakaran Pada Bangunan Gedung dan Lingkungan. Menteri Pekerjaan Umum Republik Indonesia

Peraturan Pemerintah Republik Indonesia Nomor. 36 Tahun 2005 Tentang Peraturan Pelaksanaan UndangUndang Nomor 28 Tahun 2002 Tentang Bangunan Gedung. Pemerintah Republik Indonesia.

Sugiyono (2007). Statistika Untuk Penelitian. Bandung: Alfabeta.

Sugiyono (2009). Metode Penelitian kuantitatif, kaulitatif dan $R \& D$. Bandung: Alfabeta.

Undang-Undang Republik Indonesia Nomor 24 (2007). Penanggulangan Bencana. Jakarta: DPR RI dan Presiden RI.

Winardi, A. (2006). Gempa Jogja, Indonesia dan Dunia. Jakarta: PT. Gramedia Pustaka Utama.

PenUlis:

Fajar Kabisatyo Tri Nugroho

Program Studi Magister Sistem dan Teknik Transportasi, Departemen Teknik Sipil dan Lingkungan Fakultas Teknik UGM, Jalan Grafika No. 2 Kampus UGM Yogyakarta

Email: fajar.kabisatyo.t@mail.ugm.ac.id 